\title{
Laparoscopic radiofrequency ablation for hepatocellular carcinoma
}

\section{Anna Sánchez-López ${ }^{1}$, Anna Pallisera-Lloveras ${ }^{1}$, Ramon Saiz-Mendiguren², Manuel Ferrer-Marsal ${ }^{2}$, José Carlos Vicens-Arbona ${ }^{1}$, José Andrés Cifuentes-Ródenas ${ }^{1}$, Jose Manuel Ramia ${ }^{3}$}

${ }^{1}$ Department of General Surgery, Hospital Son Llàtzer, 07198 Palma de Mallorca, Spain

${ }^{2}$ Department of Radiology, Hospital Son Llàtzer, 07198 Palma de Mallorca, Spain

${ }^{3}$ HPB Unit, Department of Surgery, Hospital Universitario de Guadalajara, 19002 Guadalajara, Spain

\begin{abstract}
Aim: The optimal treatment for hepatocellular carcinoma (HCC) is either surgical resection or liver transplantation, but only one-third of the patients are suitable candidates for surgery. Laparoscopic radiofrequency ablation (RFA) in selected patients is a safe, feasible technique, which has proved to be superior to the percutaneous approach in patients with severe liver disease or in lesions in which the percutaneous approach is impossible. The aim of this study is to present our experience with laparoscopic RFA and demonstrate its safety as an alternative therapeutic procedure in selected patients with HCC. Methods: This is a retrospective study of patients with HCC who underwent laparoscopic RFA between March 2009 and December 2014. Results: Thirty-two patients with 37 tumors underwent laparoscopic RFA. Median tumor size was $2.24 \mathrm{~cm}(0.7-4.45 \mathrm{~cm})$. Major complications occurred in 8 patients. Initial complete ablation was achieved in 94.6\% (35/37) lesions and sustained complete ablation rate was $62.85 \%$ (22/35). Overall survival rates at 1-, 2-, and 3-year were $89 \%$, $67.5 \%$, and $40 \%$, respectively. Conclusion: Laparoscopic RFA of HCC is safe and the long-term outcomes are similar to those achieved with liver resection. Further trials combining chemoembolization and RFA are needed to improve long-term outcomes and to limit local tumor progression.
\end{abstract}

Key words: Hepatocellular carcinoma; radiofrequency ablation; laparoscopic approach

\section{Address for correspondence:}

Dr. José Carlos Vicens-Arbona, Department of General Surgery, Hospital Son Llàtzer, Carretera Manacor Km. 4, 07198 Palma de Mallorca, Spain. E-mail: jcvicens@hsll.es

Received: $13-02-2015$, Accepted: $16-04-2015$

\section{INTRODUCTION}

Hepatocellular carcinoma (HCC) is the third most common cause of cancer-related deaths and the fifth most common form of cancer worldwide. ${ }^{[1]}$ Due to the nature of HCC, tumor stage, liver function, and performance status are the main prognostic variables and treatment allocation is

\begin{tabular}{|l|c|}
\hline \multicolumn{2}{|c|}{ Access this article online } \\
\hline \multirow{2}{*}{ Website: } & Quick Response Code \\
http://www.hrjournal.net/ & \\
DOI: & \\
10.4103/2394-5079.157692 & \\
&
\end{tabular}

based on the Barcelona-Clinic Liver Cancer (BCLC) staging system $^{[1-3]}$ [Figure 1]. Liver transplantation and surgical resection are considered the optimal curative strategy, ${ }^{[1-4]}$ but only one-third of patients with HCC are suitable candidates for surgery. ${ }^{[4]}$ Radiofrequency ablation (RFA) is considered the most effective local ablative therapy for patients who cannot undergo surgery due to the number and distribution of the nodules and/or the liver impairment, ${ }^{[1,2,5]}$ and can be performed percutaneously, by laparotomy or by laparoscopy. ${ }^{[6,7]}$ Laparoscopic RFA is an interesting alternative when percutaneous RFA (perRFA) cannot be performed due to the tumor location (e.g., in the case of subcapsular lesions, nodules adjacent to diaphragm without a therapeutic window, proximity to adjacent structures, and lesions in deep locations $)^{[7-10]}$ or because of the impossibility of visualizing the tumor by percutaneous ultrasound..$^{[9]}$ It has been reported 


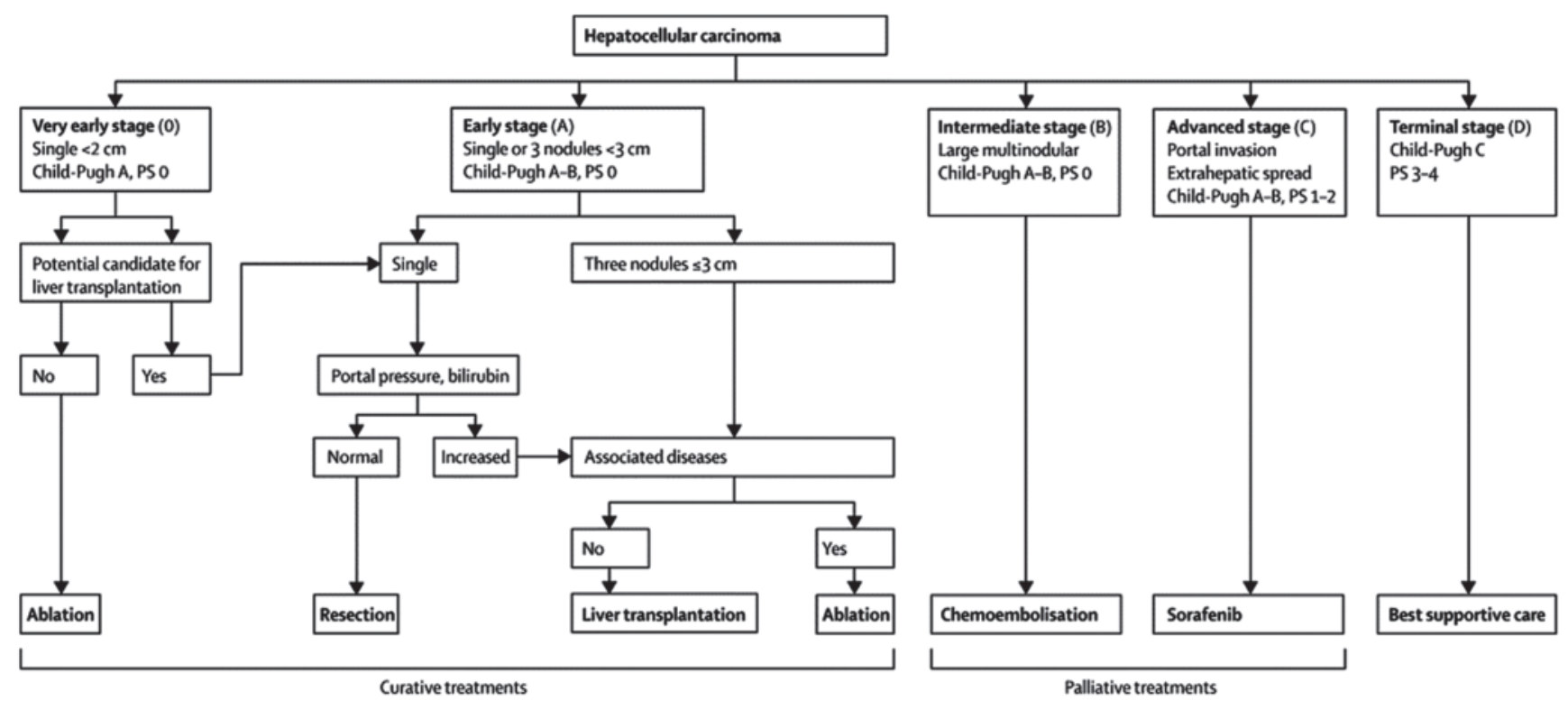

Figure 1: The Barcelona-Clinic Liver Cancer staging system for hepatocellular carcinoma (from Bruix et al. ${ }^{[2]}$ ). PS: performance status; M: metastasis classification; $\mathrm{N}$ : node classification; Bb: bilirubin; LT: liver transplantation; RFA: radiofrequency ablation; TACE: transarterial chemoembolization

that intra-operative laparoscopic ultrasound (IOLUS) permits detection of $25 \%$ of new HCC nodules ${ }^{[11]}$ and allows much more accurate staging. ${ }^{[8]}$

In this paper, we present our experience in laparoscopic RFA, analyzing the outcomes to show the safety and utility of this technique as a valid therapeutic alternative in the selected patients with HCC.

\section{METHODS}

\section{Patients and methods}

Between March 2009 and December 2014, all patients with HCC attended at the Hospital Son Llàtzer in Palma de Mallorca were entered in a prospective database. A complete medical report was obtained in each patient. Age, gender, etiology, patient characteristics such as comorbidities and liver function, size and location of the tumors, main and associated procedures, post-operative complications, treatment effectiveness and long-term results were recorded. In all, 149 patients were included in the database, with a mean of 24.83 new cases/year. Thirty-seven percent of the patients were suitable for curative treatments such as liver transplantation (which is not performed in our center), liver resection, alcoholization, and radiofrequency. The study was approved by review board of Hospital Son Llàtzer.

A retrospective study was carried out of patients undergoing laparoscopic RFA for HCC. The procedure was performed in: patients with a single lesion or a maximum of three lesions smaller than $5 \mathrm{~cm}$ who, due to medical problems or their age, were not candidates for liver transplantation; patients not suitable for liver resection in whom perRFA was contraindicated for the following reasons: (1) lesions in proximity to the viscera; (2) subcapsular lesions with a high risk of tumoral seeding; (3) lesions not visible by perRFA; and selected patients as a bridging therapy in order to meet the Milan criteria.

The follow-up period of each patient was recorded as the time from the surgical procedure until last clinical evaluation, loss to follow-up or death.

Post-operative complications were recorded and classified by the modified Clavien-Dindo Classification System. ${ }^{[12]}$

\section{Surgical procedures}

Procedures were performed with the patient under general anesthesia and in the supine position. The pneumoperitoneum was performed with insufflation of $\mathrm{CO}_{2}$ through a Veress needle inserted through a small $2-3 \mathrm{~cm}$ incision above the umbilicus. Patients with nodules in segments VI and VII were positioned in left decubitis position and an $11-\mathrm{mm}$ port was placed in the anterior axillary line. In all cases, the abdominal pressure was maintained under $12 \mathrm{mmHg}$. In our procedures we used a $30^{\circ}$ camera (Karl Storz GrubH and Co $\mathrm{KG}$, Tuttlingen, Germany) and a first complete inspection of the intraperitoneal organs were performed to rule out any extrahepatic disease. A second 5-mm trocar was placed in the epigastric area on the left side of the falciform ligament to introduce the ultrasound device. When lesions were located in the upper part of segment VIII, a hole was made through the falciform ligament in order to provide better access for the ultrasound transducer. Usually an auxiliary 5-mm trocar 
was placed on the right side. More trocars were used if it was necessary to mobilize the liver, perform adhesiolysis between the liver and other adjacent organs or release an associated procedure like cholecystectomy.

Intra-operative laparoscopic ultrasound of the entire liver parenchyma was performed to confirm location of the tumor to be treated and to rule out the presence of new nodules. In cases of lesions that were not visible by ultrasound, a piece of a $1-\mathrm{cm}(22 \mathrm{G})$ needle was inserted preoperatively into the tumor guided by computed tomography (CT) or ultrasound with a signal enhancer. We did not perform an intra-operative biopsy of the tumor prior to the RFA. Interventional radiologists came to the operating room to perform the RFA procedure and the IOLUS.

The RFA was carried out using the Cool-Tip RFA system (Covidien, Boulder, CO, USA), which uses internally cooled electrodes (ICEs) for ablation. This system circulates chilled saline to the tip of the needle electrode, thus lowering the temperature of the tissue immediately adjacent to it, minimizing tissue charring, and improving the delivery of energy to surrounding tissues. ${ }^{[13]}$

The RFA electrode was inserted through a separate percutaneous puncture and the needle was placed as parallel as possible to the plane of the ultrasound so that its entire path could be seen on the ultrasound image as it traversed the liver parenchyma. A single needle $20-\mathrm{cm}$ long and with a 2-cm tip exposure was used for tumors $<3 \mathrm{~cm}$, and for tumors $\geq 3 \mathrm{~cm}$ a cluster was used to achieve an adequate tissue margin. A 12-min RFA cycle was performed as per the manufacturer's recommendations [Figure 2].

The ICEs have sensors in their tips which measure tissue temperature and impedance at the end of the ablation procedure. ${ }^{[13]}$ The ablation was considered satisfactory if the end-tissue temperature after $12 \mathrm{~min}$ of RFA was $\geq 60{ }^{\circ} \mathrm{C}$, which is enough to cause instantaneous cellular necrosis. ${ }^{[13]}$ If the end-tissue temperature was $<60^{\circ} \mathrm{C}$, another RFA cycle lasting 6-10 min was performed.

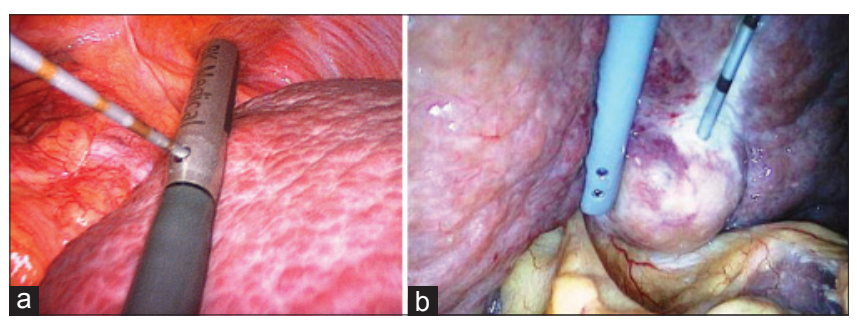

Figure 2: Surgical images of radiofrequency ablation of (a) a lesion next to the diaphragm and (b) a lesion close to duodenum and colon
After finishing the nodule ablation, the intrahepatic needle track was treated with thermocoagulation to avoid track seeding.

\section{Follow-up and definition of clinical outcome}

Treatment outcome was evaluated with an enhanced CT scan 2 months after laparoscopic RF. ${ }^{[14]}$ The inflammatory reaction makes the proper assessment of the treated nodule difficult during the $1 \mathrm{st}$ month. Thereafter, patients were followed with CT or magnetic resonance imaging and with the $\alpha$-fetoprotein every 3 months during the 1 st year and every 6 months in the 2 nd year.

Initial incomplete ablation was determined as the presence of enhanced areas within the treated nodule in the first follow-up imaging. Sustained complete ablation was defined as the absence of enhanced areas within the treated area at the end of the follow-up period.

Local tumor recurrence was defined as the presence of a growing tumor in the ablation zone after complete ablation had been determined in the first follow-up CT. Distant recurrence or new tumor progression was determined as a growing nodule occurring away from the ablation zone.

\section{Statistical analysis}

Data for all patients with HCC were recorded prospectively and introduced into a Microsoft ACCESS database. Data from patients undergoing laparoscopic RFA were analyzed retrospectively using the statistical software SPSS version 18 (SPSS Inc., Chicago, IL, USA). Continuous data were described as means and analyzed with Student's $t$-test if the distribution was normal or with Mann-Whitney $U$-test otherwise. Discontinuous data were presented as percentages and were analyzed by the Chi-square of Fisher's exact test. Overall survival curves and cumulative recurrence curves were analyzed by the Kaplan-Meier method. $P<0.05$ was considered statistically significant.

\section{RESULTS}

\section{Patient and tumor characteristics}

Between March 2009 and December 2014, 149 new cases of HCC were recorded. Eight perRFA and 40 surgical RFA were performed during this period. Only 3 lesions with radiological features of HCC from the 40 surgical RFA were treated by an open approach, while 37 lesions from 32 different patients were treated with laparoscopic RFA. We recorded the age of all patients, gender, liver function (Child-Pugh Classification), etiology [hepatitis $\mathrm{C}$ virus $\left(\mathrm{HCV}^{+}\right.$) or non- $\left.\mathrm{HCV}^{+}\right]$, and previous treatment. For tumors we recorded the number of nodules (uninodular or binodular), size, and location (subcapsular, intrahepatic or adjacent to viscera). 
All patient and tumor characteristics of the laparoscopic RFA procedures are shown in Table 1 . The main reasons for preferring laparoscopy to the percutaneous approach were: subcapsular location in 26 cases, intrahepatic location in eight cases which were difficult to define by perRFA, and location very close to adjacent viscera in three cases.

Although according to BCLC guidelines patients with liver function Child $\mathrm{C}$ are not initially candidates for RFA, one patient with Child C finally underwent RFA as palliative treatment after discussion with the Hepatobiliary Committee.

Two patients had a simultaneous surgical procedure associated with the laparoscopic RFA. One of them had a cholecystectomy due to the proximity of one of the tumors to the gallbladder, which was performed prior to the RFA. The specimen was removed by using an endobag and no tumoral seeding was reported. The other simultaneous procedure was a hysteroscopy for a uterine biopsy.

\section{Radiofrequency ablation results}

An initial complete ablation was achieved in 35 of the 37 lesions that underwent laparoscopic RFA (94.6\%). In one patient without initial complete ablation the lesion was subsequently treated by laparoscopic alcoholization and in the other transarterial chemoembolization (TACE) was performed.

\section{Morbidity}

No complications were reported during any of the laparoscopic RFA procedures nor in relation to other simultaneous techniques. Conversion to open surgery was not needed in any patient. The mean post-operative hospital stay was 4.9 days (1-30). All complications are detailed in Table 2 following the modified Clavien-Dindo Classification System. ${ }^{[12]}$ Eight patients presented some kind of complication: only one of them required emergency reintervention, following a hemoperitoneum (Clavien IIIb). One patient presented liver decompensation with mild ascites and was successfully treated with diuretics (Clavien I).

\section{Recurrence}

The median follow-up period was $28.3 \pm 2.3$ months. After achieving initial complete ablation (35 procedures), local recurrence was seen in 13 cases, after a median delay of 8.38 months (range 3-30). Six recurrent lesions were treated by TACE, 5 by new laparoscopic RFA, 1 by perRFA, 1 by sorafenib, and 1 underwent symptomatic treatment only.

Cumulative recurrence rates at 6,12 , and 36 months were $22.85 \%, 34.28 \%$, and $37.18 \%$, respectively. A higher
Table 1: Patient and tumor characteristics

\begin{tabular}{|c|c|}
\hline Variable & Result \\
\hline \multicolumn{2}{|l|}{ Patient characteristics $(n=32)$} \\
\hline Age & $63.56(38-83)$ years \\
\hline Gender (male/female) & $21 / 11$ \\
\hline \multicolumn{2}{|l|}{ Etiology } \\
\hline HCV & 23 \\
\hline Non-HCV & 9 \\
\hline \multicolumn{2}{|l|}{ Child } \\
\hline Child A & 23 \\
\hline Child B & 8 \\
\hline Child C & 1 \\
\hline Cirrhosis & 25 \\
\hline Non-cirrhosis & 7 \\
\hline \multicolumn{2}{|l|}{ Previous treatment } \\
\hline TACE & 2 \\
\hline perRFA & 1 \\
\hline \multicolumn{2}{|l|}{ Tumor characteristics $(n=37)$} \\
\hline Uninodular & 27 (84\%) \\
\hline Size & $2.24(0.7-4.5) \mathrm{cm}$ \\
\hline$\leq 2 \mathrm{~cm}$ & 19 \\
\hline $2.1-3 \mathrm{~cm}$ & 14 \\
\hline$>3 \mathrm{~cm}$ & 4 \\
\hline \multicolumn{2}{|l|}{ Location } \\
\hline Subcapsular & 26 \\
\hline Intrahepatic & 8 \\
\hline Adjacent to viscera & 3 \\
\hline
\end{tabular}

perRFA: percutaneous radiofrequency ablation; TACE: transarterial chemoembolization; HCV: hepatitis C virus

Table 2: Post-operative complications

\begin{tabular}{lc}
\hline Variable & Result \\
\hline Clavien I & 3 \\
Clavien II & 3 \\
Clavien IIIa & 0 \\
Clavien IIIb & 1 \\
Clavien IVa & 0 \\
Clavien IVb & 0 \\
Clavien V & 1 \\
\hline
\end{tabular}

local recurrence rate was observed in cirrhotic patients, $\mathrm{HCV}^{+}$, with subcapsular tumors, although the differences were not statistically significant. Twenty-two lesions of the 35, which achieved initial complete response did not present local recurrence at the end of the follow-up period, representing a rate of sustained complete ablation of $62.85 \%$. Mean follow-up was 18.72 months (range 3-44). Distant recurrence was observed in 15 patients after a mean delay of 16.66 months of follow-up (range 4-39).

\section{Mortality and survival}

One patient was lost to follow-up and 16 had died by the end of the follow-up period. No mortality related to the main procedure was reported. One death was reported 30 days after the surgical procedure in a patient with Child-Pugh $\mathrm{C}$ cirrhosis who, after RFA, also had complications related to 


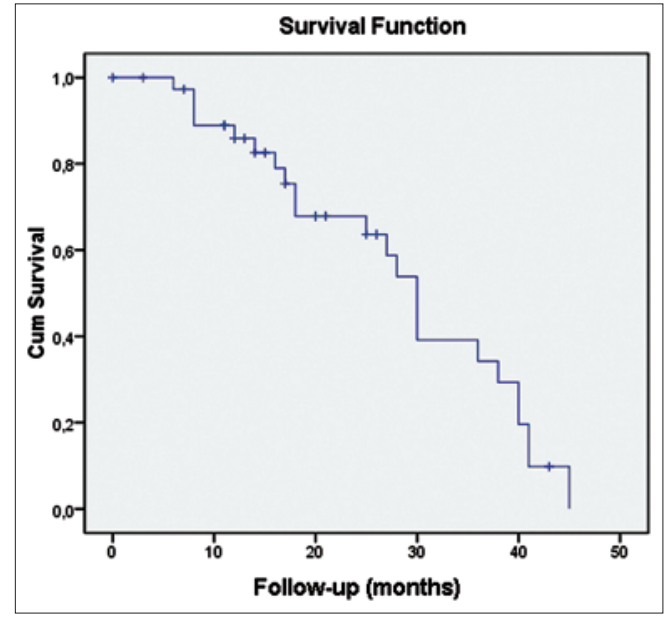

Figure 3: Overall survival of patients with hepatocellular carcinoma treated by laparoscopic radiofrequency ablation

acute vascular ulcers following severe sepsis and multi-organ failure. Only 3 deaths were related to HCC progression.

Overall survival rates at 1,2 , and 3 years were $89 \%, 67.5 \%$, and $40 \%$, respectively [Figure 3]. There was no association between local or distant recurrence and survival.

\section{DISCUSSION}

Patients with HCC have very poor prognosis. Most have poor liver function or major comorbidities at the time of diagnosis that rule out major resections; in fact, liver resection can only be performed in one third of the patients with the disease. ${ }^{[4]}$ Modern techniques such as RFA are not only potentially curative, with results similar to those achieved with liver resection, but are also minimally invasive. ${ }^{[15]}$ Laparoscopic RFA was introduced by Jung et al. ${ }^{[16]}$ in 2002 as an alternative technique in cases in which the percutaneous approach was not feasible. Another indication for the procedure is as a bridging therapy to liver transplantation for patients with HCC and terminal liver disease awaiting liver transplantation.

Compared to perRFA, the laparoscopic approach allows a complete vision of the entire intervention, especially when associated with ultrasound, which has demonstrated its utility in reporting new malignant lesions intra-operatively, ${ }^{[4,10,11]}$ and offers the possibility of treating other tumors simultaneously. Some groups have shown better oncological outcomes ${ }^{[6,16]}$ and less tumoral spread ${ }^{[9]}$ with laparoscopic RFA than with the percutaneous procedure. Moreover, simultaneous procedures can be performed together in laparoscopic RFA such as cholecystectomy or liver resection if needed. However, de la Serna et al. ${ }^{[9]}$ reported that laparoscopic RFA for HCC adjacent to the gallbladder seems to be associated with a decreased ablation efficacy in terms of both initial and long-term complete tumor response. The complications associated with perRFA reported in the literature include intraperitoneal hemorrhage, hepatic infarction, hepatic abscess formation, intestinal perforation, bile peritonitis, and carcinoma seeding. Laparoscopic RFA of HCC is associated with a low rate of major complications, most of them related to bleeding from hepatic puncture sites or trocar accesses and to iatrogenic malignant seeding. We reported only one case of major bleeding requiring reintervention, and no tumor spread was observed. There were no treatment-related deaths in our series.

In the literature, few reviews of minimally invasive RFA are available, since most surgical RFA procedures are still performed by laparotomy. ${ }^{[6]}$ Today the advantages that the laparoscopic approach can offer, in terms of creating fewer adhesions $^{[4]}$ and achieving earlier recovery, are well known. The procedure also appears to minimize the surgical insult, with less post-operative morbidity in cirrhotic patients, ${ }^{[4,9,11,16]}$ so laparoscopic RFA seems preferable to open RFA in these patients as well. ${ }^{[6]}$ The laparoscopic approach has also shown lower morbidity, lesser hepatic decompensation, and blood loss, and fewer pulmonary complications. ${ }^{[6,9,17]}$ Moreover, the increased intraperitoneal pressure necessary to perform laparoscopy reduces the portal venous flow, thus improving thermal conduction, enhancing ablation efficacy, and enlarging the ablation zone. ${ }^{[18]}$

The rates of initial complete ablation, sustained complete ablation, local recurrence, and survival in the present report are similar to those in previously published reviews, ${ }^{[4,9,10,13]}$ despite the limitation of our study in terms of its retrospective nature and its small sample size. de la Serna et al. ${ }^{[9]}$ reported an initial complete ablation rate of $94 \%$ in a study including 51 treated lesions, with a sustained complete ablation rate of $70 \%$, slightly higher than our rate of $62.85 \%$. Our 1 -year cumulative recurrence of $34.28 \%$ is an improvement on the rates of $47.4 \%$ published by Lee et al. ${ }^{[10]}$ and of $39 \%$ published by de la Serna et al. ${ }^{[9]}$

Some authors have reported that pre-treatment $\alpha$-fetoprotein and poorly differentiated HCC were independent predictors of local tumor recurrence. ${ }^{[19,20]}$ This suggests that performing an intra-operatively biopsy prior to laparoscopic RFA, as some groups do systematically, may help to predict long-term results, although it has also been reported to contribute to malignant seeding. ${ }^{[5,21]}$

Patients with HCC have a dismal prognosis, with a moderate rate of local recurrence and low long-term survival. Moreover, most of the patients who are treated with laparoscopic RFA are elderly, have severe comorbidities or have impaired liver 
function which may make prognosis even worse. Further prospective randomized controlled trials with larger sample sizes should focus on combining RFA with therapies like TACE in order to decrease local tumor progression.

As a conclusion, laparoscopic RFA of HCC is a safe and effective curative strategy in selected patients with unresectable disease, especially when the percutaneous approach is very difficult. In combination with ultrasound, this technique offers clear advantages over other approaches. The incidence of major complications within 30 days after the procedure is very low and the long-term outcomes are similar to those achieved with liver resection. Further trials are needed to assess long-term results in terms of local recurrence and survival.

\section{REFERENCES}

1. Raza A, Sood GK. Hepatocellular carcinoma review: current treatment and evidence-based medicine. World J Gastroenterol 2014;20:4115-27.

2. Bruix J, Sherman M; American Association for the Study of Liver Diseases. Management of hepatocellular carcinoma: an update. Hepatology 2011;53:1020-2.

3. European Association for the Study of the Liver; European Organisation for Research and Treatment of Cancer. EASL-EORTC clinical practice guidelines: management of hepatocellular carcinoma. J Hepatol 2012;56:908-43.

4. Casaccia M, Andorno E, Nardi I, Troilo B, Barabino G, Santori G, Valente U. Laparoscopic US-guided radiofrequency ablation of unresectable hepatocellular carcinoma in liver cirrhosis: feasibility and clinical outcome. J Laparoendosc Adv Surg Tech A 2008;18:797-801.

5. Tateishi R, Shiina S, Teratani T, Obi S, Sato S, Koike Y, Fujishima T, Yoshida H, Kawabe T, Omata M. Percutaneous radiofrequency ablation for hepatocellular carcinoma. An analysis of 1000 cases. Cancer 2005;103:1201-9.

6. Topal B, Hompes D, Aerts R, Fieuws S, Thijs M, Pennickx F. Morbidity and mortality of laparoscopic vs. open radiofrequency ablation for hepatic malignancies. Eur J Surg Oncol 2007;33:603-7.

7. Siperstein A, Garland A, Engle K, Rogers S, Berber E, String A, Foroutani A, Ryan T. Laparoscopic radiofrequency ablation of primary and metastatic liver tumors. Technical considerations. Surg Endosc 2000;14:400-5.

8. Herbold T, Wahba R, Bangard C, Demir M, Drebber U, Stippel DL. The laparoscopic approach for radiofrequency ablation of hepatocellular carcinoma-indication, technique and results. Langenbecks Arch Surg 2013;398:47-53.

9. de la Serna S, Vilana R, Sánchez-Cabús S, Calatayud D, Ferrer J, Molina V, Fondevila C, Bruix J, Fuster J, García-Valdecasas JC. Results of laparoscopic radiofrequency ablation for HCC. Could the location of the tumour influence a complete response to treatment? A single European centre experience. HPB (Oxford) 2015;17:387-93.

10. Lee SD, Han HS, Cho JY, Yoon YS, Hwang DW, Jung K, Yoon CJ, Kwon Y, Kim JH. Safety and efficacy of laparoscopic radiofrequency ablation for hepatic malignancies. J Korean Surg Soc 2012;83:36-42.

11. Santambrogio R, Podda M, Zuin M, Bertolini E, Bruno S, Cornalba GP, Costa M, Montorsi M. Safety and efficacy of laparoscopic radiofrequency ablation of hepatocellular carcinoma in patients with liver cirrhosis. Surg Endosc 2003;17:1826-32.

12. Dindo D, Demartines N, Clavien PA. Classification of surgical complications: a new proposal with evaluation in a cohort of 6336 patients and results of survey. Ann Surg 2004;240:205-13.

13. Tiong LU, Filed JB, Maddern GJ. Bimodal electric tissue ablation (BETA) compared with the Cool-Tip RFA system. ANZ J Surg 2012;82:269-74.

14. Boas FE, Do B, Louie JD, Kothary N, Hwang GL, Kuo WT, Hovsepian DM, Kantrowitz M, Sze DY. Optimal imaging surveillance schedules after liver-directed therapy for hepatocellular carcinoma. J Vasc Interv Radiol 2015;26:69-73.

15. Cillo U, Vitale A, Dupuis D, Corso S, Neri D, D’Amico F, Gringeri E, Farinati F, Vincenzi V, Zanus G. Laparoscopic ablation of hepatocellular carcinoma in cirrhotic patients unsuitable for liver resection or percutaneous treatment: a cohort study. PLoS One 2013;8:e57249.

16. Jung MK, Lee JH, Kim TS, Kim HS, Cho CM, Tak WY, Kweon YO, Kim SK, Choi YH, Chung JM. Laparoscopic and percutaneous ultrasound guided radiofrequency ablation for hepatocellular carcinoma: a preliminary study. Taehan Kan Hakhoe Chi 2002;8:209-17.

17. Zhou YM, Shao WY, Zhao YF, Xu DH, Li B. Meta-analysis of laparoscopic versus open resection for hepatocellular carcinoma. Dig Dis Sci 2011;56:1937-43.

18. Jakimowicz J, Stultiens G, Smulders F. Laparoscopic insufflation of the abdomen reduces portal venous flow. Surg Endosc 1998;12:129-32.

19. Chinnaratha MA, Sathananthan D, Pateria P, Tse E, MacQuillan G, Mosel L, Pathi R, Madigan D, Wigg AJ. High local recurrence of early-stage hepatocellular carcinoma after percutaneous thermal ablation in routine clinical practice. Eur J Gastroenterol Hepatol 2015;27:349-54.

20. Santambrogio R, Opocher E, Costa M, Capellani A, Montorsi M. Survival and intra-hepatic recurrences after laparoscopic radiofrequency of hepatocellular carcinoma in patients with liver cirrhosis. J Surg Oncol 2005;89:218-25.

21. Livraghi T, Lazzaroni S, Meloni MF, Solbiati L. The risk of tumor seeding after percutaneous ablation for hepatocellular carcinoma. $\mathrm{Br} J$ Surg 2005;92:856-8.

How to cite this article: Sánchez-López A, Pallisera-Lloveras A, Saiz-Mendiguren R, Ferrer-Marsal M, Vicens-Arbona JC, Cifuentes-Ródenas JA, Ramia JM. Laparoscopic radiofrequency ablation for hepatocellular carcinoma. Hepatoma Res 2015;1:86-91.

Source of Support: Nil. Conflict of Interest: None declared. 